Journal of Management and Bussines (JOMB)

Volume 1, Nomor 1, Juni 2019

DOI : https://doi.org/10.31539/jomb.v1i1.615

\title{
ANALISIS EFISIENSI DENGAN MENGGUNAKAN METODE DATA ENVELOPMENT ANALYSIS PADA BANK UMUM SYARIAH
}

\author{
Syifa Ikrima Fauziah $^{1}$, Erry Sunarya ${ }^{2}$, Kokom Komariah ${ }^{3}$ \\ Universitas Muhammadiyah Sukabumi ${ }^{1,2,3}$ \\ Email: Syifaikrima@gmail.com ${ }^{1}$
}

\begin{abstract}
ABSTRAK
Tujuan penelitian ini untuk mengetahui tingkat efisiensi pada bank syariah dengan menggunakan metode data envelopment analysis. Jenis penelitian ini adalah penelitian kuantitatif. Metode penelitian yang digunakan dalam penelitian ini adalah menggunakan data envelopment analyis (DEA). Teknik analisis data dengan menggunakan software DEAP version 2.1. Hasil penelitian, Bank syariah dikatakan efisien apabila mencapai tingkat 1 atau 100\%. Input yang digunakan adalah aset, total simpanan, biaya operasional dan output adalah pendapatan operasional dan pembiayaan. Penelitian ini menggunakan 5 Bank Umum Syariah yaitu Bank Muamalat Indonesia, Bank BNI Syariah, Bank BCA Syariah, Bank Syariah Mandiri dan Bank BRI Syariah selama periode 2014-2016 hanya terdapat dua bank saja yang mengalami efisiensi setiap tahunnya yaitu Bank Muamalat Indonesia dan Bank Syariah Mandiri. Simpulan, dari kelima bank syariah hanya terdapat dua bank saja yang mengalami efisiensi setiap tahunnya yaitu Bank Muamalat Indonesia dan Bank Syariah Mandiri.
\end{abstract}

Kata Kunci : Efisiensi, Bank Syariah, Data Envelopment Analysis

\section{ABSTRACT}

The purpose of this study is to determine the level of efficiency in Islamic banks using the data envelopment analysis method. This type of research is quantitative research. The research method used in this study is to use data envelopment analyis (DEA). Data analysis techniques using DEAP version 2.1 software. The results of the study, Islamic banks are said to be efficient if they reach level 1 or 100\%. The inputs used are assets, total deposits, operating costs and output are operating income and financing. This study uses 5 Sharia Commercial Banks namely Bank Muamalat Indonesia, Bank BNI Syariah, BCA Syariah Bank, Bank Syariah Mandiri and BRI Syariah Bank during the 2014-2016 period, there are only two banks that experience efficiency each year, namely Bank Muamalat Indonesia and Bank Syariah Mandiri. Conclusion, of the five Islamic banks there are only two banks that experience efficiency each year, namely Bank Muamalat Indonesia and Bank Syariah Mandiri.

Keywords: Efficiency, Islamic Bank, Data Envelopment Analysis 


\section{PENDAHULUAN}

Pada dasarnya seluruh masyarakat pada saat ini aktivitasnya selalu berhubungan dengan uang. Uang juga ada kaitannya dengan perbankan. Sistem operasional dan struktur perbankan yang efisien merupakan inti dari permasalahan perbankan, karena baik buruknya perbankan dilihat dari kebijakan operasionalnya yang efisien. Peran perbankan syariah sangat penting bagi perekonomian saat ini. Bank berperan sebagai lembaga keuangan yang fungsinya untuk penyalur dan penghimpun dana bagi masyarakat sebagai alat tukar rupiah.

Bagi suatu Negara peran perbankan sangat penting. Seiring dengan perkembangan globalisasi, bank syariah berkembang secara signifikan di dunia, terutama di negara-negara muslim.Sistem bunga yang dihapus dalam perbankan syariah menjadi altenatif utama perbankan dalam menjaga kestabilitan sistem keuangan dan mencegah terjadinya krisis global. Sektor keuangan yang berkembang di dunia menunjukan bahwa jalan menuju stabilitas keuangan akan menghadapai banyak hambatan. Stabilitas sistem keuangan berperan penting dalam mendukung pertumbuhan ekonomi dan keberlanjutan pembangunan suatu negara.

Efisiensi pada bank syariah menjadi topik untuk dianalisis dan diteliti karena sebagai sumber penghimpun dana masyarakat bank harus memperhatikan faktor yang dapat meningkatkan profitabilitas. Peran industri perbankan harus menjalankan fungsinya dengan baik agar mendapatkan kepercayaan dari konsumen mendapat pelayanan yang baik, untuk itu bank harus meningkatkan dan memberi bukti dengan prosedur kinerja yang baik. Efisiensi. Nilai efisiensi dengan menggunakan metode Data Envelopment Analysis yang merupakan salah satu teknik pengukuran yang dapat mengukur tingkat efisiensi dalam bentuk presentase. Nilai efisien menunjukan apabila pada bank tersebut mencapai tingkat $100 \%$. Dalam setiap periodenya dalam hal ini setiap tahunnya dihasilkan nilai efisiensi yang relatif terhadap bank-bank yang termasuk dalam sampel. Bank diukur secara relatif setiap tahunnya, ada satu bank yang bertindak paling efisien dari bank-bank lainnya yang terdapat dalam satu kelompok bank tersebut. 


\section{KAJIAN TEORI}

\section{Bank Syariah}

Menurut Undang-Undang Pasal 2 PBI No.6/24/PBI2004 Tentang Bank Umum yang melaksanakan kegiatan usaha berdasarkan prinsip syariah, Bank Syariah adalah Bank yang kegiatan usahanya menjalankan dengan berdasarkan prinsip syariah yang dalam kegiatannya memberikan jasa dalam lalu lintas pembayaran. Menurut jenisnya terdiri atas Bank Umum Syariah dan Bank Pembiayaan Rakyat Syariah.

\section{Efisiensi}

Efisiensi secara teoritis merupakan suatu kinerja yang merupakan salah satu kinerja yang mendasari dalam suatu organisasi. Output yang dihasilkan dengan maksimal sesuai dengan input yang ada, sebagai ukuran kinerja yang diharapkan. Pengukuran efisiensi dalam suatu akan mendapatkan tingkat input yang minimum dengan output tertentu. Hal tersebut sesuai dengan pendapat Emerson (Hasibuan, 2005)

Efisiensi adalah perbandingan yang terbaik antara input (masukan) dan output (hasil antara keuntungan dengan sumber-sumber yang dipergunakan), seperti halnya juga hasil optimal yang dicapai dengan penggunaan sumber yang terbatas. Dengan kata lain hubungan antara apa yang diselesaikan.

\section{Pendekatan Metode Data Envelopment Analysis (DEA)}

Data Envelopment Analysis (DEA) adalah teknik program linear untuk mengukur tingkat efisiensi suatu Decision Making Unit (DMU) atau unit pengambilan keputusan (UPK), pada suatu perusahaan sebagai tolak ukur dan evaluasi dalam membuat suatu keputusan. DEA pertama kali dikembangkan oleh Charnes, Cooper dan Rhodes pada tahun 1978, yang mengukur teknik input dan output menjadi multi input dan output, dengan menggunakan kerangka nilai efisiensi relative sebagai rasio input (single virtual input) dan rasio ouptput (single virtual output).

Mengaplikasikan metode DEA untuk mengukur efisiensi perusahaan dalam literature DEA disebut Unit Kegiatan Ekonomi (UKE). Dalam perkembangannya ada dua jenis model pengukuran efisiensi tersebut yaitu:

1. Constant Return to Scale (CRS) atau CCR (1978). Model CRS dikembangkan oleh Charnes, Cooper dan Rhodes (model CCR) pada tahun 1978. CRS mengasumsikan bahwa adannya model ini merupakan rasio antara penambahan input dan output 
adalah sama. Artinya apabila ada penambahan input $1 \%$ maka output juga akan meningkat $1 \%$. Asumsi lain pada model ini setiap perusahaan beroperasi pada skala yang optimal.

2. Variable Return to Scale (VRS) atau BCC (1984). Model ini dikembangkan oleh Banker, Charnes dan Chooper (BCC) pada tahun 1984, merupakan pengembangan dari model CCR. Asumsi dari model ini adalah rasio antara input dan output tidak sama. Artinya apabila ada penambahan input $1 \%$ tidak menyebabkan penambahan pada output $1 \%$ juga bisa jadi lebih besar atau lebih kecil. Asumsi lain dari model ini bahwa perusahaan belum atau tidak beroperasi pada skala yang optimal.

\section{METODE PENELITIAN}

Objek yang dipilih dalam penelitian ini adalah Bank Umum Syariah di Indonesia. Bank syariah yang dimaksud adalah Bank Muamalat Indonesia, Bank BNI Syariah, Bank BCA Syariah, Bank Syariah Mandiri dan Bank BRI Syariah. Jenis data yang digunakan yaitu Data sekunder berupa laporan keuangan yang diambil pada situs resmi Otoritas Jasa Keuangan (OJK) maupun data laporan keuangan pada masingmasing bank tahun 2014-2016.

Teknik analisis data yang digunakan dalam metode penelitian ini adalah dengan menggunakan metode Data envelopment Analysis. DEA dapat digunakan untuk mengukur tingkat efisiensi suatu Unit Kegiatan Ekonomi (UKE), yang termasuk kedalam pendekatan non parametrik. Fungsi dari DEA adalah menentukan bobot (weights) atau timbangan untuk setiap input dan output Decision Making Unit (DMU) (Coeli, 1997). Sifat dari bobot tersebut yaitu universal dan tidak negative yaitu setiap DMU sampel yang didapat dalam menggunakan seperangkat bobot yang sama untuk mengevaluasi rasionya dan rasio tersebut tidak boleh lebih dari satu (total weighted output / total weighted input $\geq 1$ ), dengan menggunakan software DEAP2.1 Farell dalam. Dengan persamaan matematis untuk Contstant Return to Scale (CRS)

Maksimal hs $=\frac{\sum r \text { ur } y r j 0}{\sum i \text { vi } x i j 0}$

Batasan

$\frac{\sum r u r y r j 0}{\sum i v i x i j 0} \leq 1$ 
$\mathrm{j}=1, \ldots, \mathrm{n}$ (untuk keseluruhan $\mathrm{j}$ )

Ur, vi $\geq \varepsilon$

Keterangan:

$\mathrm{h}$ : efisiensi teknis perbankan

$y r j$ : merupakan jumlah output $r$ yang diproduksi oleh bank $\mathrm{s}$

$u r$ : merupakan bobot output yang dihasilkan oleh bank s

vi : bobot input I yang diberikan oleh bank s, dan $\mathrm{r}$ dihitung dari $1 \mathrm{ke} \mathrm{m}$ serta $i$ dihitung dari 1 ke $n$.

\section{HASIL PENELITIAN}

Dalam melaksanakan penelitian ini, peneliti menggunakan bantuan software DEAP version 2.1 dimana menggunakan CRS. Hasil perhitungan DEA, tingkat efisiensi 5 bank syariah dapat dilihat pada tabel berikut:

Tabel 1

Hasil perhitungan efisiensi DEA Bank Umum Syariah periode 2014-2016

\begin{tabular}{cccccc}
\hline \multicolumn{5}{c}{ Skor Efisiensi } \\
\hline Periode & $\begin{array}{c}\text { Bank Muamalat } \\
\text { Indonesia }\end{array}$ & $\begin{array}{c}\text { Bank BNI } \\
\text { Syariah }\end{array}$ & $\begin{array}{c}\text { Bank BCA } \\
\text { Syariah }\end{array}$ & $\begin{array}{c}\text { Bank Syariah } \\
\text { Mandiri }\end{array}$ & $\begin{array}{c}\text { Bank BRI } \\
\text { Syariah }\end{array}$ \\
\hline 2014 & 1,000 & 0,904 & 1,000 & 1,000 & 0,904 \\
\hline 2015 & 1,000 & 0,924 & 1,000 & 1,000 & 1,000 \\
\hline 2016 & 1,000 & 0,947 & 0,940 & 1,000 & 1,000 \\
\hline
\end{tabular}

Sumber: Hasil olah data DEA

Tabel diatas menunjukkan skor efisien pada masing-masing bank syariah dimana selama tiga tahun berturut-turut Bank Muamalat Indonesia dan Bank Syariah Mandiri yang tingkat efisiennya mencapai 1 atau 100\%. Bank BCA Syariah yang mendapat nilai efisiensi pada tahun 2014 dan 2015, Bank BRI Syariah yang mendapat nilai efisiensi pada tahun 2015 dan 2016 dan Bank BNI Syariah selama periode 20142016 belum mencapai efisiensi. Berikut dapat dilihat inefisiensi dari masing-masing tiap bank syariah berdasarkan variabel input dan output dari Bank BNI Syariah, Bank BCA Syariah dan Bank BRI Syariah yaitu: 
Tabel 2

Tabel Nilai Actual, Target, Radial Movement dan Slack Movement Input dan Output Bank BNI Syariah Pada Tahun 2014-2016

\begin{tabular}{|c|c|c|c|c|c|}
\hline & $\begin{array}{l}\text { Tingkat } \\
\text { efisiensi }\end{array}$ & $\begin{array}{c}\text { Actual } \\
\text { Value }\end{array}$ & $\begin{array}{c}\text { Target } \\
\text { Value }\end{array}$ & $\begin{array}{c}\text { Radial } \\
\text { Movem } \\
\text { ent }\end{array}$ & Slack Movement \\
\hline 2014 & 0,904 & & & & \\
\hline Aset & & $\begin{array}{c}194921 \\
12.000\end{array}$ & $\begin{array}{c}194921 \\
12.000\end{array}$ & 0.000 & 0.000 \\
\hline $\begin{array}{c}\text { Total } \\
\text { simpanan }\end{array}$ & & $\begin{array}{l}162464 \\
05.000\end{array}$ & $\begin{array}{l}162464 \\
05.000\end{array}$ & 0.000 & 0.000 \\
\hline $\begin{array}{c}\text { Biaya } \\
\text { Operasional }\end{array}$ & & $\begin{array}{c}126405 \\
5.000\end{array}$ & $\begin{array}{c}792174 \\
.172\end{array}$ & $\begin{array}{c}- \\
121692 \\
.941\end{array}$ & -350187.887 \\
\hline $\begin{array}{l}\text { Pendapatan } \\
\text { Operasional }\end{array}$ & & $\begin{array}{c}257318 \\
8.000\end{array}$ & $\begin{array}{c}177494 \\
7.913\end{array}$ & $\begin{array}{c}- \\
247725 \\
.626\end{array}$ & -550514.460 \\
\hline Pembiayaan & & $\begin{array}{l}150441 \\
57.000\end{array}$ & $\begin{array}{l}135958 \\
27.841\end{array}$ & $\begin{array}{c}- \\
144832 \\
9.159\end{array}$ & 0.000 \\
\hline 2015 & 0,924 & & & & \\
\hline Aset & & $\begin{array}{c}230176 \\
67.000 \\
\end{array}$ & $\begin{array}{c}230176 \\
67.000 \\
\end{array}$ & 0.000 & 0.000 \\
\hline $\begin{array}{c}\text { Total } \\
\text { Simpanan }\end{array}$ & & $\begin{array}{l}193227 \\
56.000 \\
\end{array}$ & $\begin{array}{l}193227 \\
56.000 \\
\end{array}$ & 0.000 & 0.000 \\
\hline $\begin{array}{c}\text { Biaya } \\
\text { Operasional }\end{array}$ & & $\begin{array}{c}146027 \\
8.000\end{array}$ & $\begin{array}{c}134912 \\
7.149\end{array}$ & $\begin{array}{c}- \\
111150 \\
.851 \\
\end{array}$ & 0.000 \\
\hline $\begin{array}{l}\text { Pendapatan } \\
\text { Operasional }\end{array}$ & & $\begin{array}{c}257318 \\
8.000\end{array}$ & $\begin{array}{c}237732 \\
6.639\end{array}$ & $\begin{array}{c}- \\
195861 \\
.361 \\
\end{array}$ & 0.000 \\
\hline Pembiayaan & & $\begin{array}{l}177650 \\
97.000\end{array}$ & $\begin{array}{l}164128 \\
84.851\end{array}$ & $\begin{array}{c}- \\
135221 \\
2.149 \\
\end{array}$ & 0.000 \\
\hline 2016 & 0,947 & & & & \\
\hline Asset & & $\begin{array}{l}283141 \\
75.000\end{array}$ & $\begin{array}{c}283141 \\
75.000\end{array}$ & 0.000 & 0.000 \\
\hline $\begin{array}{c}\text { Total } \\
\text { Simpanan }\end{array}$ & & $\begin{array}{c}242330 \\
09.000 \\
\end{array}$ & $\begin{array}{c}242330 \\
09.000 \\
\end{array}$ & 0.000 & 0.000 \\
\hline $\begin{array}{c}\text { Biaya } \\
\text { Operasional }\end{array}$ & & $\begin{array}{c}169070 \\
3.000\end{array}$ & $\begin{array}{c}159783 \\
0.935\end{array}$ & $\begin{array}{c}- \\
90380 . \\
343\end{array}$ & -2491.722 \\
\hline $\begin{array}{l}\text { Pendapatan } \\
\text { Operasional }\end{array}$ & & $\begin{array}{c}296072 \\
4.000\end{array}$ & $\begin{array}{c}270901 \\
4.908\end{array}$ & $\begin{array}{c}- \\
158272 \\
.181 \\
\end{array}$ & -93436.911 \\
\hline Pembiayaan & & $\begin{array}{c}204936 \\
09.000\end{array}$ & $\begin{array}{l}193980 \\
76.896\end{array}$ & $\begin{array}{c}- \\
109553 \\
2.104\end{array}$ & 0.000 \\
\hline
\end{tabular}

Sumber : Hasil olah data 
Selama periode 2014-2016 Bank BNI Syariah mengalami inefisiensi pada tahun 2014 yaitu pada Biaya Operasional, Pendapatan Operasional dan Pembiayaan. Sedangkan tiga tahun berturut-turut Aset dan Total Pembiayaan mencapai nilai efisiensi. Dengan target value dan radial movement juga nilai slack movement yang dapat menjadi solusi untuk mencapai nilai yang efisien.

Tabel 3

Tabel Nilai Actual, Target, Radial Movement dan Slack Movement Input dan Output Bank BCA Syariah Pada Tahun 2016

\begin{tabular}{|c|c|c|c|c|c|}
\hline & $\begin{array}{l}\text { Tingkat } \\
\text { Efisiensi }\end{array}$ & $\begin{array}{c}\text { Actual } \\
\text { Value }\end{array}$ & $\begin{array}{c}\text { Target } \\
\text { Value }\end{array}$ & $\begin{array}{c}\text { Radia } \\
\quad l \\
\text { Move } \\
\text { ment }\end{array}$ & $\begin{array}{c}\text { Slack } \\
\text { Movement }\end{array}$ \\
\hline 2016 & 0,940 & & & & \\
\hline Aset & & $\begin{array}{c}499560 \\
7.000 \\
\end{array}$ & $\begin{array}{c}499560 \\
7.000 \\
\end{array}$ & 0.000 & 0.000 \\
\hline Total Simpanan & & $\begin{array}{c}384227 \\
2.000 \\
\end{array}$ & $\begin{array}{c}397290 \\
9.228 \\
\end{array}$ & 0.000 & $\begin{array}{c}130637.22 \\
8 \\
\end{array}$ \\
\hline $\begin{array}{c}\text { Biaya } \\
\text { Operasional }\end{array}$ & & $\begin{array}{c}352823 \\
.000\end{array}$ & $\begin{array}{c}271488 \\
.582\end{array}$ & $\begin{array}{c}- \\
2126 \\
8.382\end{array}$ & -60066.036 \\
\hline $\begin{array}{l}\text { Pendapatan } \\
\text { Operasional }\end{array}$ & & $\begin{array}{c}777404 \\
.000\end{array}$ & $\begin{array}{c}501488 \\
.815\end{array}$ & $\begin{array}{c}- \\
4686 \\
2.380 \\
\end{array}$ & $\begin{array}{c}- \\
229052.80 \\
5\end{array}$ \\
\hline Pembiayaan & & $\begin{array}{c}346282 \\
6.000\end{array}$ & $\begin{array}{c}325408 \\
4.770\end{array}$ & $\begin{array}{c}- \\
2087 \\
41.23 \\
0\end{array}$ & 0.000 \\
\hline
\end{tabular}

Sumber: Hasil Olahdata DEA

Selama periode 2014-2015 Bank BCA Syariah mencapai nilai efisiensi, namun pada tahun 2016 mengalami inefisiensi yaitu pada biaya operasional yang mempunyai nilai actual sebesar 352823.000 dimana target value sebesar 271488.582 harus dikurangi sebesar 21268.382 dengan nilai slack movement sebesar 60066.336. variabel kedua yaitu pendapatan operasional dengan nilai actual sebesar 777404.000 dan target value sebesar 501488.815 harus dikurangi sebesar 46862.380 dengan nilai slack movement sebesar 229052.805 dan variabel ketiga yaitu pembiayaan dengan nilai actual sebesar 3462826.000 dan target value sebesar 3254084.770 harus dikurangi sebesar 208741.230 . 
Tabel 4

Tabel Nilai Actual, Target, Radial Movement dan Slack Movement Input dan Output Bank BRI Syariah Pada Tahun 2014

\begin{tabular}{|c|c|c|c|c|c|}
\hline & $\begin{array}{c}\text { Tingkat } \\
\text { Efisiensi }\end{array}$ & Actual Value & Target Value & $\begin{array}{c}\text { Radial } \\
\text { Movement }\end{array}$ & $\begin{array}{c}\text { Slack } \\
\text { Movement }\end{array}$ \\
\hline 2014 & 0,904 & & & & \\
\hline Aset & & 20341033.000 & 20341033.000 & 0.000 & 0.000 \\
\hline $\begin{array}{c}\text { Total } \\
\text { Pembiayaan }\end{array}$ & & 16947590.000 & 16947590.000 & 0.000 & 0.000 \\
\hline $\begin{array}{c}\text { Biaya } \\
\text { Operasional } \\
\end{array}$ & & 1165466.000 & 824240.757 & -111946.638 & -229278.605 \\
\hline $\begin{array}{l}\text { Pendapatan } \\
\text { Operasional }\end{array}$ & & 2165169.000 & 1851051.474 & -207971.223 & -106146.303 \\
\hline Pembiayaan & & 15691631.000 & 14184400.990 & -1507230.010 & 0.000 \\
\hline
\end{tabular}

Sumber : Hasil Olahdata DEA

Bank BRI Syariah adalah bank terakhir yang masuk kategori inefisiensi yang terjadi pada tahun 2014. Pada tiga variabel yaitu variabel pertama biaya operasional dengan nilai actual sebesar 1165466.000 dan target value sebesar 824240.757 harus dikurangi sebesar 111946.638 dengan slack movement sebesar 229278.605. variabel yang kedua yaitu pendapatan operasional dengan nilai actual sebesar 2165169.000 dan nilai target value sebesar 1851051.474 harus dikurangi sebesar 207971.223 dengan slack movement sebesar 106146.303 dan variabel ketiga yaitu pembiayaan dengan nilai actual sebesar 15691631.000 dan target value sebesar 14184400.990 harus dikurangi sebesar 1507230.010 agar mencapai nilai yang efisien.

\section{PEMBAHASAN}

Hasil penelitian ini menunjukkan bahwa rata-rata tingkat efisiensi pada 5 bank syariah yaitu Bank Muamalat Indonesia, Bank BNI Syariah, Bank BCA Syariah, Bank Syariah Mandiri dan Bank BRI Syariah relatif stabil. dengan tiga variabel input dan dua variabel output, variabel input yaitu Aset, Total Simpanan dan Biaya Operasional sedangkan variabel output yaitu Pendapatan Operasional dan Pembiayaan. Hasil penelitian ini sama dengan penelitian Sani (2017) dimana masing-masing variabel input dan output yang digunakan sama. Dengan menggunakan metode Data Envelopment Analysis dapat mengetahui tingkat efisien dan inefisien masing-masing bank syariah. Hal ini sama dengan hasil penelitian Sri (2016) selama periode penelitian pada tahun 
2014-2016 hanya ada dua bank syariah yang mengalami efisiensi secara berturut-turut yaitu Bank Muamalat Indonesia dan Bank Syariah Mandiri.

Telah dijelaskan bahwa dalam analisis metode DEA skor efisiensi memiliki nilai 1 atau 100\%. Skor 1 berarti bank tersebut dapat menggambarkan kemampuan dalam mengoptimalkan sumber daya yang dimilki. Sedangkan bila skor yang didapat jauh dari 100 berarti bank tersebut inefisien dalam mengoptimalkan sumber daya yang dimiliki dan belum mampu menjalankan peran bank tersebut belum optimal sebagai lembaga intermediasi.

Selain itu ada nilai actual dan nilai target. Nilai actual merupakan nilai input dan output yang dimiliki sedangkan nilai target merupakan nilai yang disarankan oleh DEA dalam perhitungan input output agar menjadi efisien. Asumsi yang digunakan dalam penelitian ini adalah Constant Return to Scale (CRS) karena suatu unit DMU antar bank memiliki kemiripan karakteristik satu dengan lainnya yang berada dalam skala yang optimal. Model ini menunjukkan nilai technical efficiency atau nilai dari profit efficiency dalam setiap DMU.

Berdasarkan hasil perhitungan DEA yang berasumsikan constant return to scale (CRS) dengan menggunakan bantuan software DEAP 2.1, dapat dilihat tingkat efisiensi lima bank syariah berikut ini:

Tabel 5

Tingkat Efisiensi Bank Syariah 2014-2016

\begin{tabular}{|c|c|c|c|c|c|}
\hline \multirow[t]{2}{*}{ No } & \multirow[t]{2}{*}{ Nama Bank } & \multicolumn{3}{|c|}{ Efisiensi Pertahun } & \multirow[t]{2}{*}{ Rata-rata bank } \\
\hline & & 2014 & 2015 & 2016 & \\
\hline 1. & Bank Muamalat Indonesia & 1.000 & 1.000 & 1.000 & 1.000 \\
\hline 2. & Bank BNI Syariah & 0.904 & 0.924 & 0.947 & 0.925 \\
\hline 3. & Bank BCA Syariah & 1.000 & 1.000 & 0.940 & 0.98 \\
\hline 4. & Bank Syariah mandiri & 1.000 & 1.000 & 1.000 & 1.000 \\
\hline 5. & Bank BRI Syariah & 0.904 & 1.000 & 1.000 & 0.968 \\
\hline Rata-1 & pertahun & 0.962 & 0.985 & 0.977 & \\
\hline
\end{tabular}

Sumber: hasil penelitian (data diolah)

Berdasarkan tabel diatas, hasil perhitungan dengan menggunakan metode DEA menunjukkan bahwa secara rata-rata tingkat efisiensi pada lima bank syariah pada tahun 2014-2016 mengalami fluktuasi dengan nilai yang hampir mencapai efisien. Pada tahun 2014 rata-rata tingkat efisiensi bank syariah mencapai 0.962 lalu meningkat pada tahun 
2015 sebesar 0.985 namun pada tahun 2016 rata-rata efisiensi menurun sebesar 0.008 menjadi 0.977 .

Jika dilihat dari masing-masing bank syariah, pada tahun 2014 ada tiga bank yang mencapai efisiensi sebesar 1.000 yaitu Bank Muamalat Indonesia, Bank BCA Syariah dan Bank Syariah Mandiri, sedangkan dua bank syariah lainnya belum mencapai efisiensi (inefisien) yaitu Bank BNI Syariah sebesar 0.904 dan Bank BRI Syariah sebesar 0.904 .

Pada tahun 2015 efisiensi pada bank syariah meningkat ada empat bank yang mencapai tingkat efisiensi sebesar 1.000 yaitu Bank Muamalat Indonesia, Bank BCA Syariah, Bank Syariah Mandiri dan Bank BRI Syariah, sedangkan hanya satu bank syariah yang mengalami inefisiensi yaitu Bank BNI Syariah sebesar 0.924.

Pada tahun 2016 Bank Mumalat Indonesia, Bank Syariah Mandiri dan Bank BRI Syariah tetap mencapai tingkat efisiensi sebesar 1.000, sedangkan Bank BNI Syariah nilai rata-rata meningkat namun belum pernah mencapai efisiensi (inefisiensi) sebesar 0.947 dan Bank BCA Syariah selama dua periode berturut-turut mencapai sebesar 1.000 pada tahun 2016 efisiensi menurun sebesar 0.06 menjadi 0.940 .

\section{SIMPULAN}

Berdasarkan hasil perhitungan dan pembahasan yang telah diuraikan dengan menghitung nilai efisiensi pada masing-masing bank umum syariah menggunakan metode Data Envelopment Analysis selama periode 2014-2016. Dari kelima bank syariah yaitu Bank Muamalat Indonesia, Bank BNI Syariah, Bank BCA Syariah, Bank Syariah Mandiri dan Bank BRI Syariah hanya terdapat dua bank saja yang mengalami efisiensi setiap tahunnya yaitu Bank Muamalat Indonesia dan Bank Syariah Mandiri. 


\section{DAFTAR PUSTAKA}

Coelli, T.J. (1997), A Multi-Stage Methodology for the solution of Oriented DEA Models, mimeo, Centre for Efficiency and Productivity Analysis, University of New England, Armidale.

Danial R. Deni M. (2018). Pedoman Penulisan Skripsi. Sukabumi: Program Studi Administrasi Bisnis Fakultas Ilmu Administrasi dan Humaniora Universitas Muhammadiyah Sukabumi.

Hasibuan, Malayu S.P. (2005): Manajemen Sumber Daya Manusia. Jakarta : Bumi Akasara.

Lestari, Intan Sri. (2016). Efisiensi Bank Umum Syariah di Indonesia Menggunakan Metode Data Envelopment Analysis (DEA) (Studi pada Bank Mega Syariah, Bank Muamalat Indonesia, Bank BNI Syariah dan Bank Syariah Mandiri Tahun 2013-2014)

Putri, M.S. (2017). Analisis Efisiensi Bank Umum Syariah (BUS) di Indonesia dengan Menggunakan Metode Data Envelopment Analysis (DEA) Periode 20132015.UIN Jakarta : tidak diterbitkan. 